PREPARED FOR THE U.S. DEPARTMENT OF ENERGY, UNDER CONTRACT DE-AC02-76CH03073

PPPL-3652

PPPL-3652

UC-70

Spherical Torus Center Stack Design

by

C. Neumeyer, P. Heitzenroeder, C. Kessel, M. Ono,

M. Peng, J. Schmidt, R. Woolley, and I. Zatz

January 2002

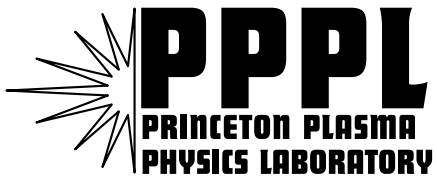

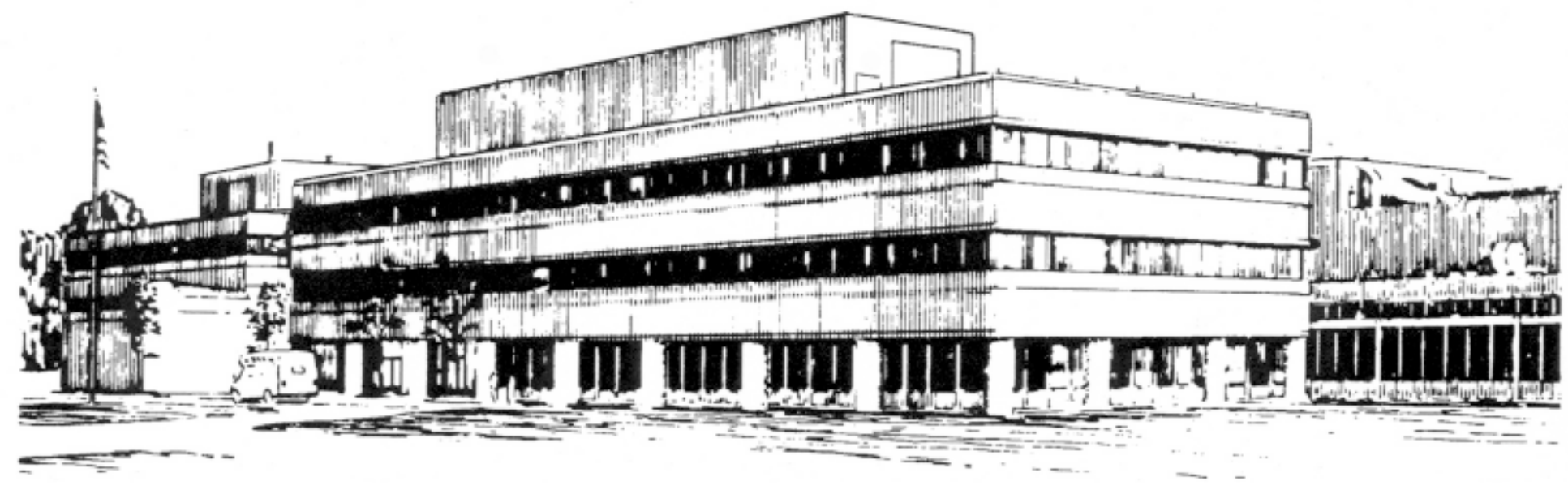

PRINCETON PLASMA PHYSICS LABORATORY PRINCETON UNIVERSITY, PRINCETON, NEW JERSEY 


\section{PPPL Reports Disclaimer}

This report was prepared as an account of work sponsored by an agency of the United States Government. Neither the United States Government nor any agency thereof, nor any of their employees, makes any warranty, express or implied, or assumes any legal liability or responsibility for the accuracy, completeness, or usefulness of any information, apparatus, product, or process disclosed, or represents that its use would not infringe privately owned rights. Reference herein to any specific commercial product, process, or service by trade name, trademark, manufacturer, or otherwise, does not necessarily constitute or imply its endorsement, recommendation, or favoring by the United States Government or any agency thereof. The views and opinions of authors expressed herein do not necessarily state or reflect those of the United States Government or any agency thereof.

\section{Availability}

This report is posted on the U.S. Department of Energy's Princeton Plasma Physics Laboratory Publications and Reports web site in Fiscal Year 2002. The home page for PPPL Reports and Publications is: http://www.pppl.gov/pub_report/

DOE and DOE Contractors can obtain copies of this report from:

U.S. Department of Energy

Office of Scientific and Technical Information

DOE Technical Information Services (DTIS)

P.O. Box 62

Oak Ridge, TN 37831

Telephone: (865) 576-8401

Fax: (865) 576-5728

Email: reports@adonis.osti.gov

This report is available to the general public from:

National Technical Information Service

U.S. Department of Commerce

5285 Port Royal Road

Springfield, VA 22161

Telephone: 1-800-553-6847 or

(703) 605-6000

Fax: (703) 321-8547

Internet: http://www.ntis.gov/ordering.htm 


\title{
Spherical Torus Center Stack Design
}

\author{
C. Neumeyer, P. Heitzenroeder, C. Kessel, M. Ono, M. Peng ${ }^{\dagger}$, J. Schmidt, R. Woolley, I. Zatz, \\ Princeton University Plasma Physics Laboratory*, 'Oak Ridge National Laboratory
}

Abstract-- The low aspect ratio spherical torus (ST) configuration requires that the center stack design be optimized within a limited available space, using materials within their established allowables. This paper presents certer stack design methods developed by the National Spherical Torus Experiment (NSTX) Project Team during the initial design of NSTX, and more recently for studies of a possible next step ST (NSST) device.

\section{INTRODUCTION}

$\mathrm{D}$ esign point selection requires parametric study relying on simple analytic solutions to characterize performance in terms of plasma and engineering quantities, short of detailed analysis using, e.g. finite element methods. Many excellent papers have been written on this subject for conventional tokamaks [1] and also for STs [2,3]. This paper presents the method used by the NSTX team which includes some perhaps interesting new ideas being considered for NSST. The focus is on engineering issues related to pulsed copper/copper alloy magnets and, further, to the Toroidal Field (TF) and Ohmic Heating $(\mathrm{OH})$ coils associated with the "center stack" of the ST device.

\section{DeSIGN IsSUES}

\section{A. Requirements}

Performance requirements for the TF system are the toroidal field $\mathrm{B}_{\mathrm{t}}$ to be produced at radius $\mathrm{R}_{0}$, and flat top duration. For the $\mathrm{OH}$ system the primary requirement is to produce a specified flux swing over the time of plasma current duration. Secondary requirements relate to the coil height, which determines the fraction of $\mathrm{OH}$ flux coupled to the plasma, and the stray field. Since the $\mathrm{OH}$ coil surrounds the inner legs of the TF coil in an ST, the $\mathrm{OH}$ coil also sets the TF height.

\section{B. Engineering Constraints}

While the complete design of the $\mathrm{TF}$ and $\mathrm{OH}$ coils and the integrated center stack requires detailed analysis of many aspects, the main design drivers are as follows.

\section{- OH Coil}

- Conductor temperature rise and mechanical stress

- TF Coil Inner Legs

- Conductor temperature rise and mechanical stress

- Insulation shear stress

- Integrated Center Stack

- Peak power, typically at start of flat top (SOFT)

- Peak energy, typically at end of flat top (EOFT)

- Overall height

${ }^{*}$ Under USDOE Contract \# DE-AC02-76CH03073
Methods for estimating these factors are presented herein (except for the TF insulation shear, which is highly dependant on the torque reaction scheme). However, it is emphasized that careful judgment is required in choosing allowables and margins. The challenge is to select, based on simple analysis, a design point which will withstand the scrutiny of detailed analysis with, in the end, satisfactory margins.

\section{Methodology}

Methods presented here are in use to study options for a next step ST. However, they are derived from earlier work on NSTX [4] and MAST [2] and can be applied more generally.

\section{A. OH Coil}

To rough-out the thermal and mechanical conditions, the following simplified $\mathrm{OH}$ waveform is assumed.

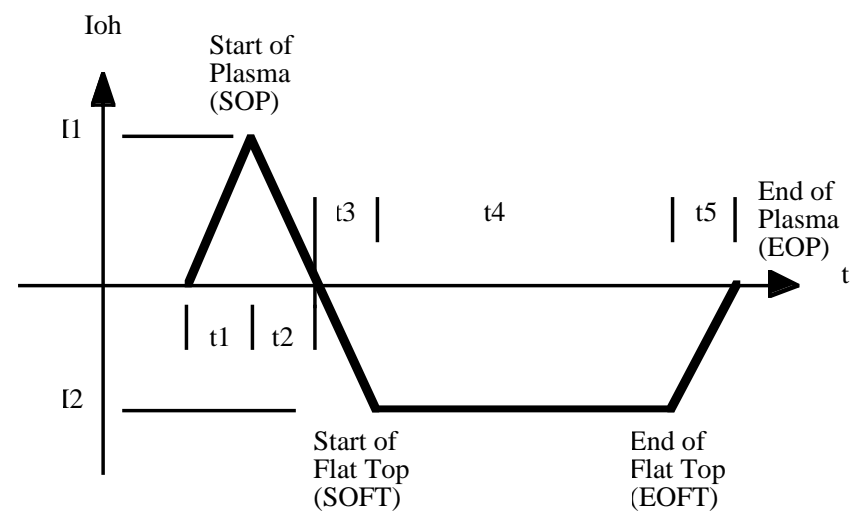

Fig 1. Simplified OH Current Waveform

$\mathrm{OH}$ conductor materials will be cooled, in the case the NSST, to liquid nitrogen $\left(\mathrm{LN}_{2}\right)$ temperature $(80 \mathrm{~K})$ prior to the pulse and allowed to heat to $373 \mathrm{~K}(100 \mathrm{C})$ at the end of the pulse. Optimum performance is realized when materials are operated at their low temperature stress limit at SOP and their high temperature stress limit at EOFT, and at their thermal limit at EOP. Toward this end, for the $\mathrm{OH}$ waveform shown in Fig. 1 , an asymmetry in the $\mathrm{OH}$ current waveform can be chosen to optimized performance. Assuming that the EM stress is due to Ioh only, then...

$\frac{I_{1}}{I_{2}}=\sqrt{\frac{\sigma_{\text {cold }}}{\sigma_{\text {hot }}}} \equiv K_{\text {asym }}$

A second benefit of asymmetric $\mathrm{OH}$ operation is reduced dissipation during the relatively long plasma flat top time. A third benefit is that the peak $\mathrm{OH}$ power which coincides with the peak TF power at SOFT is reduced, such that the total composite power peak imposed on the facility is reduced. 
To maximize the flux swing available from the $\mathrm{OH}$ solenoid for NSST a novel approach has been identified which involves the use of a two part $\mathrm{OH}$ coil. Studies have shown that such a coil can increase the flux by $50 \%$ compared to a constant current density all-copper coil. The outer coil is wound with copper $(\mathrm{Cu})$ conductor and is operated at a current density such that the material is at both thermal and mechanical limits. The minimum inner radius of the outer coil is determined by the allowable hoop stress. Then the inner coil is wound with a beryllium copper $(\mathrm{BeCu})$ alloy material $(\mathrm{C} 17510)$ and is operated at a current density such that the material is at either its thermal or mechanical allowable, which ever is limiting.

\section{OH Thermal Calculations}

The total I2T of the $\mathrm{OH}$ pulse is....

$$
\begin{aligned}
& \sum I^{2} T=I_{1}^{2}\left(\frac{t_{1}}{3}+\frac{t_{2}}{3}\right)+I_{2}^{2}\left(\frac{t_{3}}{3}+t_{4}+\frac{t_{5}}{3}\right) \\
& =I_{1}^{2}\left(\frac{t_{1}}{3}+\frac{t_{2}}{3}\right)+\frac{I_{1}^{2}}{K_{\text {asym }}^{2}}\left(\frac{t_{3}}{3}+t_{4}+\frac{t_{5}}{3}\right)
\end{aligned}
$$

With equivalent square wave (ESW) current $\mathrm{I}_{\mathrm{ESW}}=\mathrm{I}_{1} \ldots$

$$
T_{E S W}=\left(\frac{t_{1}}{3}+\frac{t_{2}}{3}\right)+\frac{\left(\frac{t_{3}}{3}+t_{4}+\frac{t_{5}}{3}\right)}{K_{\text {asym }}^{2}}
$$

A $20 \%$ margin in temperature rise is allocated to nuclear heating and magnetoresistivity effects. For ordinary ohmic heating, curve fits are used to develop $\mathrm{G}\left(=\mathrm{J}^{2} \mathrm{~T}_{\text {esw }}\right)$ functions for $\mathrm{Cu}$ and $\mathrm{BeCu}$ over the temperature range of interest.

$$
\begin{aligned}
& G_{C u}(T)=-6.45 E 16+1.02 E 15 T-2.61 E 12 T^{2}+2.74 E 9 T^{3} \\
& G_{B e C u}(T)=-1.54 E 16+1.93 E 14 T-3.02 E 10 T^{2}+1.41 E 8 T^{3}
\end{aligned}
$$

The current density $\mathrm{J}$ which is allowable given a temperature limit $\mathrm{T}_{\text {allow }}$ can be determined as follows...

$$
J=\sqrt{\frac{G\left(T_{\text {allow }}\right)-G\left(T_{0}\right)}{T_{E S W}}}
$$

Given a packing fraction $K_{\mathrm{pf}}$, then, the allowable current density has an average value of....

$$
J_{\text {avg }}=J K_{p f}
$$

\section{OH Stress Calculations}

The following formulae are used to estimate the conductor stress in the $\mathrm{OH}$ solenoid. Axial stress (relatively small) is ignored, and only the hoop stress is considered. For a two part $\mathrm{OH}$ solenoid, on the outer coil, the maximum hoop stress occurs at the inner bore of the coil [5] and can be estimated as follows.

$$
\sigma=\mathrm{J} * \mathrm{~B}\left\{\begin{array}{l}
\frac{\left[(7+5 v) \mathrm{R}_{\mathrm{o}}{ }^{4}-8(2+v) \mathrm{R}_{\mathrm{o}} \mathrm{R}_{\mathrm{i}}{ }^{3}+3(3+v) \mathrm{R}_{\mathrm{i}}{ }^{4}\right]}{24\left(\mathrm{R}_{\mathrm{o}}-\mathrm{R}_{\mathrm{i}}\right)\left(\mathrm{R}_{\mathrm{o}}{ }^{2}-\mathrm{R}_{\mathrm{i}}{ }^{2}\right)} \\
-\frac{(1+2 v) \mathrm{R}_{\mathrm{o}} \mathrm{R}_{\mathrm{i}}}{3\left(\mathrm{R}_{\mathrm{o}}-\mathrm{R}_{\mathrm{i}}\right)}+\frac{(1+3 v) \mathrm{R}_{\mathrm{i}}{ }^{2}}{8\left(\mathrm{R}_{\mathrm{o}}-\mathrm{R}_{\mathrm{i}}\right)} \\
+\frac{\mathrm{R}_{\mathrm{o}}{ }^{2}}{24}\left[\frac{\left.(7+5 v) \mathrm{R}_{\mathrm{o}}{ }^{2}-8(2+v) \mathrm{R}_{\mathrm{o}} \mathrm{R}_{\mathrm{i}}+3(3+v) \mathrm{R}_{\mathrm{i}}{ }^{2}\right)}{\left(\mathrm{R}_{\mathrm{o}}-\mathrm{R}_{\mathrm{i}}\right)\left(\mathrm{R}_{\mathrm{o}}{ }^{2}-\mathrm{R}_{\mathrm{i}}{ }^{2}\right)}\right]
\end{array}\right\}
$$

where:

$$
\begin{aligned}
& \mathrm{R}_{\mathrm{o}}=\text { outer radius of conductor pack } \\
& \mathrm{R}_{\mathrm{i}}=\text { inner radius of conductor pack } \\
& v=\text { Poisson's Ratio }
\end{aligned}
$$

Here B is the field within the bore of the outer coil due to its own current....

$B=\mu_{0} J_{\text {avg }}\left(R_{o}-R_{i}\right) * f f$

Where ff is the form factor which accounts for the finite length of the coil....

$$
f f=\frac{\Delta Z}{\sqrt{\Delta Z^{2}+\left[\frac{\left(R_{o}+R_{i}\right)}{2}\right]^{2}}}
$$

and $\Delta \mathrm{Z}$ is the height of the coil. The height of the $\mathrm{OH}$ coil needs to exceed that of the plasma by some amount to reduce leakage flux and minimize stray vertical field. Based on NSTX, a ratio between $\mathrm{OH}$ coil height and plasma height in the range 1.2 to 1.4 is typically assumed for NSST.

On the inner coil, the maximum hoop stress occurs at the inner bore of the coil, due to its own current plus the J x B force with the background field of the outer coil [5]....

$\sigma=\mathrm{J} * \mathrm{~B}\left\{\frac{(2+v)\left[2 \mathrm{R}_{\mathrm{o}}{ }^{2}+\mathrm{R}_{\mathrm{o}} \mathrm{R}_{\mathrm{i}}+\mathrm{R}_{\mathrm{i}}{ }^{2}-\frac{\left(\mathrm{R}_{\mathrm{o}}+\mathrm{R}_{\mathrm{i}}\right)(1+2 v) \mathrm{R}_{\mathrm{i}}}{2+v}\right]}{3\left(\mathrm{R}_{\mathrm{o}}+\mathrm{R}_{\mathrm{i}}\right)}\right\}$

Here $R_{0}$ and $R_{i}$ are the outer and inner radii of the inner coil, $\mathrm{J}$ is the current density of the inner coil, and B is field due to the outer coil. Finally, the double swing flux produced by each part of the $\mathrm{OH}$ coil is equal to....

$$
\Phi_{d s}=f f * \frac{\mu_{0} \pi J_{a v g}}{3}\left(R_{o}^{3}-R_{i}^{3}\right)\left(1+1 / K_{\text {asym }}\right)
$$

\section{OH Power and Energy Calculations}

The peak power will occur just prior to Start of Flat Top (SOFT), at the end of the plasma current ramp up. To calculate the power, the coil inductance and resistance at SOFT needs to be calculated. Although this could be done on a one-turn basis, a particular number of turns is chosen to provide some idea of the power supply requirements. Assuming a current $I$ per turn, the corresponding number of turns $\mathrm{N}$ for a particular field can be computed as follows. 


$$
N=\frac{B}{f f\left(\mu_{0} I \Delta Z\right)}
$$

On this basis the number of turns in the inner and outer coils can be calculated. Then the inductance of the $\mathrm{OH}$ coil, with a total of $\mathrm{N}_{\mathrm{oh}}$ turns, is as follows...

$$
\begin{aligned}
& L_{o h}=\frac{\text { flux }}{\text { ampere }- \text { turns }} \\
& =\frac{\Phi_{d s}}{\left(1+1 / k_{\text {asym }}\right) N_{o h} I} * N_{o h}^{2}=\frac{\Phi_{d s} N_{o h}}{I\left(1+1 / k_{\text {asym }}\right)}
\end{aligned}
$$

The $\mathrm{G}$ function can be used to estimate the temperature of the conductors at SOFT as follows.

$$
\begin{aligned}
& G=G\left(T_{o}\right)+\Delta G \\
& \Delta G=\int J^{2}(t)=\frac{I_{E S W}^{2} T_{E S W}}{C S A}
\end{aligned}
$$

Curve fits are used to develop inverse $\mathrm{G}$ functions for $\mathrm{Cu}$ and $\mathrm{BeCu}$ as follows.

$$
\begin{aligned}
& T_{C u}(G)=79.37+1.35 E-15 G+6.29 E-33 G^{2}+1.38 E-49 G^{3} \\
& T_{\text {BeCu }}(G)=80.55+5.63 E-15 G-8.15 E-33 G^{2}+6.03 E-49 G^{3}
\end{aligned}
$$

\begin{tabular}{|c|c|c|}
\hline \multicolumn{3}{|c|}{ RESISTIVITY CHARACTERISTICS } \\
\hline & $\mathrm{Cu}$ & $\mathrm{BeCu}$ \\
\hline Resistivity $\rho(\mu \Omega-m) @ 293 \mathrm{~K}$ & 1.72 & 2.529 \\
\hline Temp coefficient $\alpha\left(\operatorname{deg}^{-1} \mathrm{~K}\right)$ & 0.0041 & 0.0025 \\
\hline
\end{tabular}

With the temperatures known, the resistance of the inner and outer coils can be calculated using resistivity data as follows.

TABLE 1

The driving voltage at SOFT is...

$V_{o h}=\frac{\left(I * R_{o h}+L_{o h} * I / t_{3}\right)}{K_{s y m}}$

The power is...

$$
P_{\text {soft }}=V_{o h} * I
$$

The peak energy requirement will occur at EOFT. Curve fits are used to develop the $\mathrm{H}$ functions $\left(\mathrm{J} / \mathrm{m}^{3}\right)$ for $\mathrm{Cu}$ and $\mathrm{BeCu}$. These functions relate the dissipated energy to the temperature rise, and are of the form...

$$
\begin{aligned}
& H_{C u}(T)=-1.54 E 8+1.41 E 6 T+5929.6 T^{2}-5.29 T^{3} \\
& H_{B e C u}(T)=-1.36 E 8+1.13 e E T+7329.5 T^{2}-7.54 T^{3}
\end{aligned}
$$

The temperature of the coils is computed in the same manner as for SOFT. Then, the energy dissipation is...

$$
\Delta H=H(T)-H\left(T_{o}\right)
$$

$W=\Delta H^{*} C S A^{*} L$

Finally, total energy is the sum of dissipated and stored...

$W_{\text {eoft }}=W_{\text {diss }}+1 / 2 L_{\text {oh }}\left(I / K_{\text {asym }}\right)^{2}$

\section{B. TF Coil}

The following simplified TF coil shape is assumed.

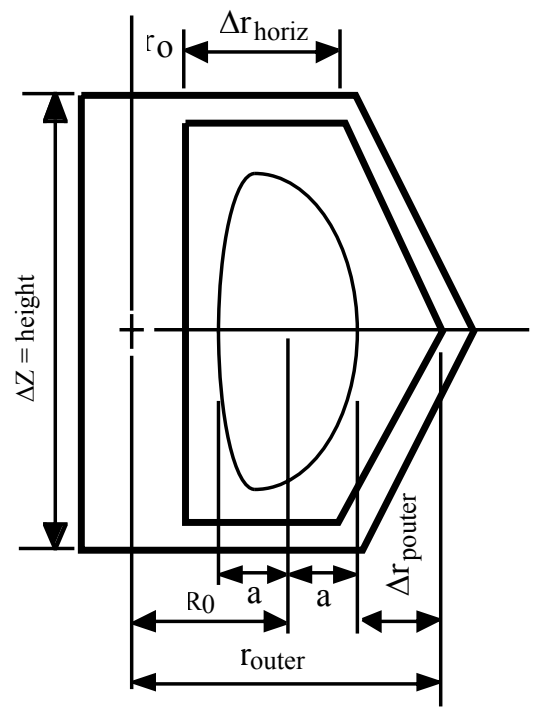

Fig. 2 Simplified TF Coil Representation

Based on NSTX, the ratio of TF coil height to plasma height $\mathrm{TF}$ in the range 1.6 to 1.8 is appropriate for NSST. The length of the horizontal limbs is assumed equal $2 *$ a.

\section{TF Thermal, Power, and Energy Calculations}

Thermal performance of the coil is assessed by performing a simple simulation of the TF current waveform. The required current from $\mathrm{N}$ turns is...

$$
N I=2 \pi \frac{R_{0} B}{\mu_{0}}
$$

The inductance is obtained by integrating the flux enclosed as follows...

$$
\Phi=\int_{0}^{\text {router }} \frac{\mu_{0} I}{2 \pi r} H(r) d r
$$

where I is the current enclosed, which linearly increases from zero at $r=0$ to the full current $I$ at the outer radius of the inner legs, and $\mathrm{H}(\mathrm{r})$ is the height of the bore of the coil, assumed equal to "height" out through the horizontal limbs, and then linearly decreasing to zero thereafter over the distance " $\Delta \mathrm{r}_{\text {pouter }}$ ". Then the inductance is...

$L_{t f}=\frac{\Phi N^{2}}{I}$ 
The total resistance of $\mathrm{N}$ series inner legs of the coil is...

$$
R_{\text {inner }}=\rho \frac{L N}{A_{\text {conductor }}}
$$

where L is assumed equal to "height" and $\rho$ is the resistivity which varies with temperature and current, due to the magnetoresistivity effect. The fractional increase due to magnetorestivity can be described via a function $\mathrm{F}[6]$ where:

$\mathrm{F}=10^{\left(-2.662+0.3168 \mathrm{X}+0.6229 \mathrm{X}^{2}-0.1839 * \mathrm{X}^{3}+0.01827 * \mathrm{X}^{4}\right)}$

$X=\log _{10}\left[\frac{B}{(1+k(T-273))}\right]$

$\mathrm{B}=$ average transverse field ( $\mathrm{B}$ at $\mathrm{r}=70.7 \%$ of inner leg radius)

$\mathrm{T}=$ temperature of interest

$\mathrm{k}=$ temperature coefficient of resistance

Curve fits were used to develop a function for the specific heat of copper as follows.

$$
Q_{C u}(T)=-82.36+4.95 T-0.019 T^{2}+2.5 E-5 T^{3}
$$

For small increments, temperature rise is approximated as...

$$
\Delta T \approx \frac{I^{2} R}{Q(T)}
$$

Outer leg resistance is assumed constant and equal to a fraction of the inner leg resistance at maximum temperature.

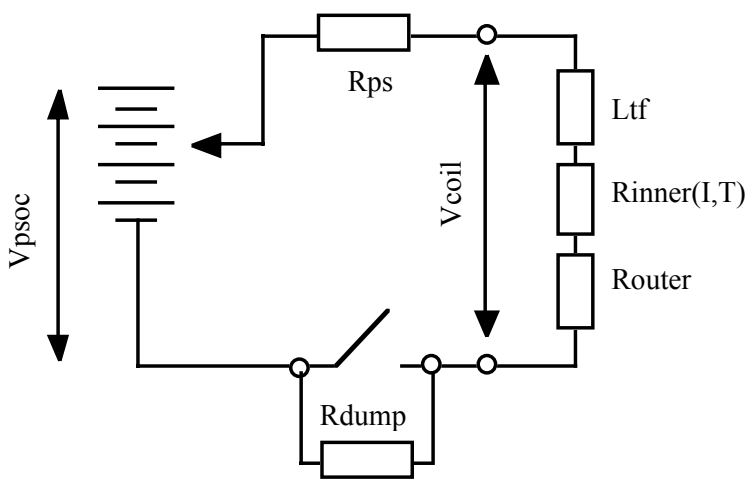

Fig. 3. TF Equivalent Circuit

The simulation circuit is shown in figure 3. A dump resistor, normally bypassed, can be introduced if the power supply trips at full current, thereby reducing the $\mathrm{L} / \mathrm{R}$ time constant and the additional dissipation which must be anticipated. Circuit response is simulated using Euler integration...

$\Delta I=\frac{\left[V_{p s o c}-I\left(R_{p s}+R_{\text {inner }}+R_{\text {outer }}\right)\right] \Delta t}{L}$

with the inner leg temperature and resistance updated each time step. Flat top must end when the prospective temperature rise due to an $\mathrm{L} / \mathrm{R}$ decay of the current would bring the final temperature to the limit. This is estimated by taking the total stored energy, apportioning it between the inner and outer legs and dump resistor in proportion to their resistances, and dividing by the heat capacity...

$\Delta T_{L R}=\frac{\left[1 / 2 L I^{2}\right] \frac{R_{\text {inner }}}{\left(R_{\text {inner }}+R_{\text {outer }}+R_{\text {dump }}\right)}}{Q}$

\section{TF Stress Calculations}

To assess the inner leg stresses, the outer leg contribution to the vertical force needs to be included. An optimum outer leg is moment-free and imposes minimal vertical load on the inner legs by using a "bow" shaped constant tension form. Variations described herein further develop earlier bow coil concepts [7] so as to achieve practical dimensions.

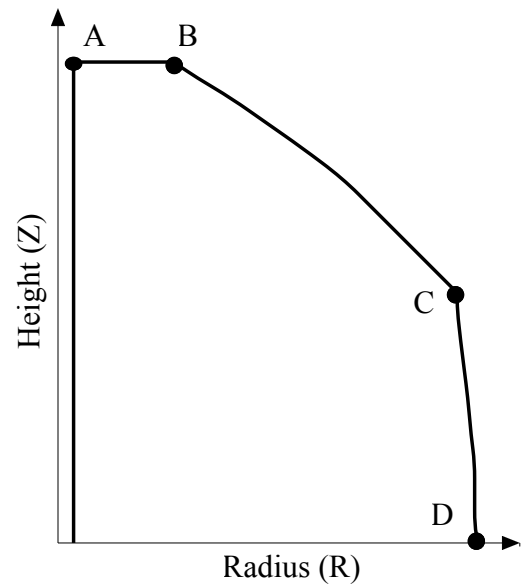

Fig. 4 Path of Current Center of TF Outer Leg

In figure 4, "A" is located at the radius of the effective current center of the inner leg. The segment between " $A$ " and " $B$ " is the radial flag. The segment between " $\mathrm{B}$ " and " $\mathrm{C}$ " is a constant tension section of the outer leg. At "C" a force can be applied by a structural ring to alter the shape of the outer leg. The segment between " $\mathrm{C}$ " and " $\mathrm{D}$ " is another constant tension section. " $\mathrm{D}$ " corresponds to the outer leg current center intersection with the midplane.

The total integrated vertical force on the outer leg in one half plane is independent of the path taken from points $\mathrm{A}$ to $\mathrm{D}$.

$$
F_{v}=\int_{r 1}^{r 2} I_{r}(r) B_{\varphi}(r) d r=\frac{1}{2} \frac{\mu_{0} I^{2}}{2 \pi} \ln \left(\frac{R_{2}}{R_{1}}\right)=\frac{I B_{0} R_{0}}{2} \ln \left(\frac{R_{2}}{R_{1}}\right)
$$

where:

$$
\begin{aligned}
& \mathrm{I}_{\mathrm{r}}(\mathrm{r})=\text { radial component of TF current at radius } \mathrm{r} \\
& \mathrm{B}_{\varphi}(\mathrm{r})=\text { toroidal field at radius } r \text {, avg. across conductor } \\
& \mathrm{B}_{0}=\text { toroidal field at plasma major radius } \mathrm{R}_{0} \\
& \left.\mathrm{R}_{2}=\text { radius to current center in outer leg (point } A\right) \\
& \left.\mathrm{R}_{1}=\text { radius to current center in inner leg (point } \mathrm{D}\right)
\end{aligned}
$$

It is noted that, in the above derivation:

$$
\mathrm{B}_{\varphi}(\mathrm{r})=\frac{1}{2}\left[\frac{\mu_{0} I}{2 \pi r}\right]
$$


due to the fact that $\mathrm{B}$ varies from maximum at the inside of the outer leg to zero on the outside, so the current interacts, on average, with $1 / 2$ of the value of $B$ on the inside. For the inner leg, with circular cross section extending to the outer radius $r_{0}$ :

$$
F=\int_{r=0}^{r=r_{o}} I(r) B(r) d r=\frac{\pi \mu_{0} J^{2} r_{o}^{4}}{8}=\frac{\mu_{0} I^{2}}{8 \pi}
$$

An equivalent representation consists of a filament proceeding from an effective current center at $R_{1}$ and then to $r_{0}$ which produces the same total integrated force:

$$
F=\int_{r=R 1}^{r=r o} I(r) B(r) d r=\frac{\mu_{0} I^{2}}{2 \pi} \ln \left(\frac{r_{o}}{R_{1}}\right)
$$

Equating the above two results produces the following for $R_{1}$ :

$$
R_{1}=\frac{\mathrm{r}_{\mathrm{o}}}{\varepsilon^{1 / 4}}=0.78 r_{o}
$$

For the outer leg the current center coincides with the simple geometric center of the conductor.

The relative fractions of $F_{v}$ which are applied at points $A$ and $\mathrm{D}$ can be controlled by tailoring the shape of the outer leg. The constant tension $T$ shape is obtained by joining together constant tension arc segments such that:

$\rho=\frac{d S}{d \theta}=\frac{T}{P}$

where:

$$
\begin{array}{ll}
\rho=\text { radius of curvature } & \theta=\text { arc angle } \\
S=\text { arc length } & P=\text { force per unit length }
\end{array}
$$

If $f$ is the fraction of the total vertical force allowed to appear on the inner leg then the constant tension curve can be generated by numerical integration of:

$$
\frac{\Delta S}{\Delta \theta}=(1-f) * r * \ln \left(\frac{R 2}{R 1}\right)
$$

The limit on vertical force which can be applied to the inner leg depends on the other components of stress arising from EM and thermal effects. The flow of TF current causes an inward "pinching" force on the column, as well as torsion arising from the JxB force with the poloidal fields. The pinching causes compression which is maximum at the center, whereas the torsion causes shear which is maximum at the outer edge of the inner leg. It is assumed that the former is the limiting factor, so the shear stress neglected in this analysis. With constant current density the inward radial force within the inner leg conductor varies linearly with radius since:

$B=\frac{\mu_{0} I}{2 \pi r}=\frac{\mu_{0} J r}{2} \therefore J x B=\frac{\mu_{0} J^{2} r}{2}$

This situation is similar to that of a rotating cylindrical shaft where the centrifugal force is proportional to radius. Approximate formulae [8] for the principal stresses are:

$$
\begin{aligned}
& \sigma_{r r}=\left(-\frac{B_{\max }^{2}}{2 \mu_{0}}\right)\left(\frac{3-2 v}{2(1-v)}\right)\left(1-\left(\frac{r}{a}\right)^{2}\right) \\
& \sigma_{\varphi \varphi}=\left(-\frac{B_{\max }^{2}}{2 \mu_{0}}\right)\left(\frac{3-2 v}{2(1-v)}-\frac{1+2 v}{2(1-v)}\left(\frac{r}{a}\right)^{2}\right) \\
& \sigma_{z z}=\left(-\frac{B_{\max }^{2}}{2 \mu_{0}}\right)\left(\frac{v}{1-v}\right)\left(1-2\left(\frac{r}{a}\right)^{2}\right)
\end{aligned}
$$

where:

$r=$ radius within conductor $a=$ outer radius of conductor $v=$ Poission's ratio $\quad \mathrm{B}_{\max }=\mathrm{B}$ at $\mathrm{r}=\mathrm{a}, \mathrm{B}_{\mathrm{ma}}=\mu_{0} \mathrm{I} / 2 \pi \mathrm{a}$

The combined (Von Mises) stress can be calculated as....

$\sigma_{\text {VonMises }}=\sqrt{\frac{\left(\sigma_{r r}-\sigma_{\varphi \varphi}\right)^{2}+\left(\sigma_{\varphi \varphi}-\sigma_{z z}^{\prime}\right)^{2}+\left(\sigma_{z z}^{\prime}-\sigma_{r r}\right)^{2}}{2}}$

where...

$\sigma_{z z}{ }^{\prime}=\left(-\frac{B_{\max }^{2}}{2 \mu_{0}}\right)\left(\frac{v}{1-v}\right)\left(1-2\left(\frac{r}{a}\right)^{2}\right)+\Delta$

... and $\Delta$ is the stress due to the vertical force EM force $F_{v}$ as well as pre-compression and/or thermally induced stresses along the $\mathrm{z}$ axis. Allowing for a pre-compression force $\mathrm{F}_{0}$, along with an additional force $\mathrm{F}_{\mathrm{s}}$ due to thermal expansion, where $\mathrm{F}_{\mathrm{s}}=k \Delta \mathrm{L}$, $\mathrm{k}$ being the spring constant of the structure:

$$
\Delta=\frac{f^{*} F_{v}-\left(F_{0}+k \Delta L\right)}{A_{n e t}}
$$

The design must consider the expected temperatures at start of pulse (SOP), start and end of flat top (SOFT, EOFT), and end of pulse (EOP), combining the EM forces only for the SOFT and EOFT states. The parameters to be adjusted include:

- $\quad$ Fraction $f$ of vertical force allowed on inner leg

- Values of pre-compression $\mathrm{F}_{0}$ and spring constant $k$

- Location $(r, z)$ and force at " $C$ ", location (r) of " $B$ "

The optimum pre-compression force results in a balance between the fraction of allowable stress at SOFT and EOP.

\section{REFERENCES}

[1] J. D. Galambos et al, "System Studies of Compact Ignition Tokamaks", Fusion Technolog, vol. 13, p. 93-114, Jan. 1988.

[2] G. Voss et al, "Centre Column Design for the MAST Spherical Tokamak", Proceedings of Symposium on Fusion Technology (SOFT), Elsevier Science, 1994, p. 953

[3] R. J. Colchin, et al, "The Design of the Center Core of a Spherical Tokamak", Fusion Technology, vol. 31, p. 350-369, May 1997.

[4] C. L. Neumeyer et al, "Engineering Design of the NSTX", Fusion Engineering and Design, vol. 54, p. 275-319, 2001

[5] R. Roark \& W. Young, Formulas for Stress \& Strain, McGraw-Hill, p. 505 , Table 32, eq. 1e, 1f.

[6] National Institute of Standards \& Technology (NIST) Monograph \#177

[7] P. Bonanos, "Bow-Shaped Toroidal Field Coils", IEEE Transactions on Magnetics, vol. MAG-17, No. 5, p. 1942-1946, Sept. 1981.

[8] A. Love, A Treatise on the Mathematical Theory of Elasticity, Dover Publications, 1944 


\section{External Distribution}

Plasma Research Laboratory, Australian National University, Australia

Professor I.R. J ones, Flinders University, Australia

Professor J oão Canalle, Instituto de Fisica DEQ/IF - UERJ , Brazil

Mr. Gerson O. Ludwig, Instituto Nacional de Pesquisas, Brazil

Dr. P.H. Sakanaka, Instituto Fisica, Brazil

The Librarian, Culham Laboratory, England

Library, R61, Rutherford Appleton Laboratory, England

Mrs. S.A. Hutchinson, JET Library, England

Professor M.N. Bussac, Ecole Polytechnique, France

Librarian, Max-Planck-Institut für Plasmaphysik, Germany

J olan Moldvai, Reports Library, MTA KFKI-ATKI, Hungary

Dr. P. Kaw, Institute for Plasma Research, India

Ms. P.J . Pathak, Librarian, Insitute for Plasma Research, India

Ms. Clelia De Palo, Associazione EURATOM-ENEA, I taly

Dr. G. Grosso, Instituto di Fisica del Plasma, Italy

Librarian, Naka Fusion Research Establishment, J AERI, J apan

Library, Plasma Physics Laboratory, Kyoto University, J apan

Research Information Center, National Institute for Fusion Science, J apan

Dr. O. Mitarai, Kyushu Tokai University, J apan

Library, Academia Sinica, Institute of Plasma Physics, People's Republic of China

Shih-Tung Tsai, Institute of Physics, Chinese Academy of Sciences, People's Republic of China

Dr. S. Mirnov, TRINITI, Troitsk, Russian Federation, Russia

Dr. V.S. Strelkov, Kurchatov Institute, Russian Federation, Russia

Professor Peter Lukac, Katedra Fyziky Plazmy MFF UK, Mlynska dolina F-2, Komenskeho Univerzita, SK-842 15 Bratislava, Slovakia

Dr. G.S. Lee, Korea Basic Science Institute, South Korea

Mr. Dennis Bruggink, Fusion Library, University of Wisconsin, USA

Institute for Plasma Research, University of Maryland, USA

Librarian, Fusion Energy Division, Oak Ridge National Laboratory, USA

Librarian, Institute of Fusion Studies, University of Texas, USA

Librarian, Magnetic Fusion Program, Lawrence Livermore National Laboratory, USA

Library, General Atomics, USA

Plasma Physics Group, Fusion Energy Research Program, University of California at San Diego, USA

Plasma Physics Library, Columbia University, USA

Alkesh Punjabi, Center for Fusion Research and Training, Hampton University, USA

Dr. W.M. Stacey, Fusion Research Center, Georgia Institute of Technology, USA

Dr. J ohn Willis, U.S. Department of Energy, Office of Fusion Energy Sciences, USA

Mr. Paul H. Wright, Indianapolis, Indiana, USA 
The Princeton Plasma Physics Laboratory is operated by Princeton University under contract with the U.S. Department of Energy.

\author{
Information Services \\ Princeton Plasma Physics Laboratory \\ P.O. Box 451 \\ Princeton, NJ 08543
}

Phone: 609-243-2750

Fax: 609-243-2751

e-mail: pppl_info@pppl.gov

Internet Address: http://www.pppl.gov 